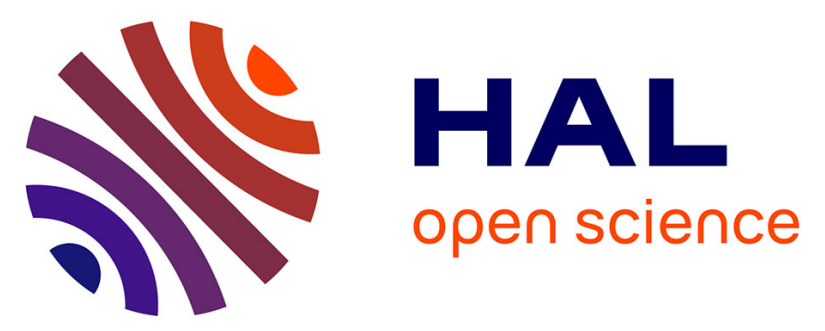

\title{
Generation of Multicomponent Molecular Cages using Simultaneous Dynamic Covalent Reactions
}

\author{
Wojciech Drożdż, Camille Bouillon, Sébastien Richeter, Mihail Barboiu, \\ Clément Sébastien, Artur R. Stefankiewicz, Sébastien Ulrich
}

\section{To cite this version:}

Wojciech Drożdż, Camille Bouillon, Sébastien Richeter, Mihail Barboiu, Clément Sébastien, et al.. Generation of Multicomponent Molecular Cages using Simultaneous Dynamic Covalent Reactions. Chemistry - A European Journal, 2017, 23 (71), pp.18010 - 18018. 10.1002/chem.201703868 . hal01680391

\section{HAL Id: hal-01680391 \\ https://hal.umontpellier.fr/hal-01680391}

Submitted on 25 May 2021

HAL is a multi-disciplinary open access archive for the deposit and dissemination of scientific research documents, whether they are published or not. The documents may come from teaching and research institutions in France or abroad, or from public or private research centers.
L'archive ouverte pluridisciplinaire HAL, est destinée au dépôt et à la diffusion de documents scientifiques de niveau recherche, publiés ou non, émanant des établissements d'enseignement et de recherche français ou étrangers, des laboratoires publics ou privés. 


\title{
Generation of Multicomponent Molecular Cages using Simultaneous Dynamic Covalent Reactions.
}

\author{
Wojciech Drożdż, ${ }^{[\mathrm{d},[\mathrm{b}]}$ Camille Bouillon, ${ }^{[\mathrm{c}]}$ Clément Kotras, ${ }^{[\mathrm{d}]}$ Sébastien Richeter, ${ }^{[\mathrm{d}]}$ Mihail Barboiu, ${ }^{[\mathrm{e}]}$ \\ Sébastien Clément, ${ }^{[\mathrm{d}]}$ Artur R. Stefankiewicz, ${ }^{*[\mathrm{a}],[\mathrm{b}]}$ and Sébastien Ulrich ${ }^{*[\mathrm{c}]}$
}

\begin{abstract}
Cage compounds are very attractive structures for a wide range of applications and there is ongoing interest in finding effective ways to access this kind of complex structures, particularly those possessing dynamic adaptive features. Here we report the accessible synthesis of new type of organic cage architectures, possessing two different dynamic bonds within one structure: hydrazones and disulfides. Implementation of three distinct functional groups (i.e. thiols, aldehydes and hydrazides) in the structure of two simple building blocks resulted in their spontaneous and selective self-assembly into aromatic cage-type architectures. These organic cages contain up to ten components linked together by twelve reversible covalent bonds. The advantage provided by the presented approach is that these cage structures can adaptively self-sort from a complex virtual mixture of polymers or macrocycles and that dynamic covalent chemistry enables their deliberate disassembly through controlled component exchange.
\end{abstract}

\section{Introduction}

Cage compounds have attracted considerable interest due to their potential function as "nano-containers" for (bio)molecular recognition, delivery applications, and supramolecular catalysis. $^{[1]}$

Supramolecular chemistry has been particularly successful in the synthesis of complex supramolecular cages using coordination chemistry ${ }^{[2]}$ and hydrogen bond interactions. ${ }^{[3]}$ On the other hand, major advances have been recently made in the preparation of dynamic covalent cage-type compounds using dynamic covalent chemistry (DCC). ${ }^{[4],[5]}$ The first advantage provided by DCC is that it enables the rapid production of large

[a] W. Drożdż, Prof. Dr. A. R. Stefankiewicz

Faculty of Chemistry, Adam Mickiewicz University, Umultowska 89b,

61-614 Poznań, Poland.

E-mail: ars@amu.edu.pl

[b] W. Drożdż, Prof. Dr. A. R. Stefankiewicz

Centre for Advanced Technologies, Adam Mickiewicz University, Umultowska 89c, 61-614 Poznań, Poland.

[c] Dr. C. Bouillon, Dr. S. Ulrich

Institut des Biomolécules Max Mousseron (IBMM), UMR 5247, CNRS, Université de Montpellier, ENSCM, Ecole Nationale

Supérieure de Chimie de Montpellier, 8 rue de l'Ecole Normale, 34296 Montpellier cedex 5, France.

E-mail: sebastien.ulrich@enscm.fr

[d] C. Kotras, Dr. S. Richeter, Dr. S. Clément

Institut Charles Gerhardt, UMR 5253, CNRS, Université de Montpellier, ENSCM, Place Eugène Bataillon, 34095 Montpellier Cedex 05, France.

[e] Dr. M. Barboiu

Institut Européen des Membranes, IEM, UMR-5635, Université de Montpellier, ENSCM, CNRS, Adaptive Supramolecular Nanosystems Group, Place Eugène Bataillon, CC 047, F-34095 Montpellier, France.

Supporting information for this article is given via a link at the end of the document. and diverse dynamic combinatorial libraries (DCL), ${ }^{[6]}$ in which some interesting and unexpected constituents may be expressed, either spontaneously or by medium/templating effects. The second advantage of DCC is that since it involves reversible covalent reactions, it produces dynamic systems which are capable of self-correcting in order to convert intermediates into thermodynamic products. Finally, the third advantage provided by DCC is that it enables access to covalent robust structures which are yet dynamic and capable of adapting to an environmental pressure such as the presence of a competitor that operates through component exchange. ${ }^{[7]}$

The use of multiple reversible covalent reactions and building blocks of high functionality is of interest to expand the structural diversity of constituents expressed in a DCL. ${ }^{[6]}$ However, this comes at a cost and requires powerful analytical tools to characterize such constitutionally complex systems. Therefore, sets of reversible covalent reactions which operate independently of each other are useful to engineer more focused and controllable multi-level DCL. ${ }^{[8]}$ Several reports have shown that condensation reactions (imine, (acyl)hydrazone) and disulfides can operate orthogonally to each other. For instance, Otto et al., ${ }^{[9]}$ Furlan et al., ${ }^{[10]}$ and Fulton et al. ${ }^{[11]}$ reported systems where acylhydrazone and disulfide exchange can be triggered independently at different $\mathrm{pH}$. Typically, acylhydrazone and disulfide exchange exclusively under acidic and basic conditions, respectively. The external control of the reactivity using different reaction conditions can be exploited for instance for stepwise molecular motions. ${ }^{[12]}$ On the other hand, one may also wish to conduct both transformations independently (i.e. with high chemoselectivity, avoiding cross-reactions) but in the same reaction conditions for moving more effectively up the complexity ladder - from small molecules to complex nanostructures through one-pot multi-steps self-assembly processes. In this perspective, while Otto and co-workers showed that using a nucleophilic organocatalyst of hydrazone exchange can help find reactions conditions where both reactions operates simultaneously, ${ }^{[9]}$ Alfonso and co-workers recently demonstrated that the presence of DMSO in DCL can significantly promote thiol oxidation into disulfides as well as disulfide exchange, and even at acidic $\mathrm{pH}^{\left[{ }^{[13]}\right.}$ thereby opening a practical way to carry out both reversible covalent reactions in the same reaction conditions.

The generation of organic cages through bottom-up selfassembly represents an interesting challenge. Cage-type compounds are large multi-component entities which bear strong interest as functional systems for their host-guest recognition properties. In this context, imine bonds have been used for generating organic cages. For instance, Warmuth and co-workers showed cage formation by reacting pre-organized cavitands grafted with aldehyde groups with diamines. ${ }^{[14]}$ Cooper and co-workers reported the one-pot assembly of organic cages through 12 imine bonds ${ }^{[15]}$ and their corresponding triplyinterlocked assemblies. ${ }^{[16]}$ More recently, Barboiu and co- 
workers reported ligand- and metal-driven selection in iminebased organic cages. ${ }^{[17]}$ Besides condensation reactions such as imine and (acyl)hydrazone formation, disulfides represent another prominent tool in DCC. ${ }^{[18]}$ Of particular interest, Stefankiewicz and Sanders reported that cage-type compounds can be expressed in disulfide-based DCL, either spontaneously or through templating effects. ${ }^{[19]}$ More specifically, cages featuring rigid aromatics attract great interest for (bio)molecular recognition. Nitschke et al. have inserted aromatics in metallosupramolecular cages, ${ }^{[20]}$ Davis et al. have designed aromatic cages for sugar recognition, ${ }^{[21]}$ Alfonso et al. have shown the self-assembly of pseudo-peptidic cages from aromatic aldehydes, ${ }^{[22]}$ and very recently Stang et al. reported metallosupramolecular cages featuring fluorescent aromatics for amino acid sensing. ${ }^{[23]}$ Yet, the generation of multi-component organic cages by a one-pot self-assembly process employing a set of independent reversible covalent reactions operating simultaneously remain limited to a few examples combining imine and olefin metathesis, ${ }^{[24]}$ or imine and boronic ester. ${ }^{[25]}$ To the best of our knowledge, no investigation into the synthesis of water soluble, multicomponent cages via two distinct dynamic covalent bonds has been published. We report herein the onepot formation of a new class of multicomponent organic cages using acylhydrazones and disulfides as independent dynamic covalent reactions (Scheme 1). These molecular structures consist of up to ten components connected through up to twelve dynamic covalent bonds. We show two examples of structurally distinct cage systems i.e. tripodal and fluorescent tetrapodal cage architectures. Finally, we demonstrate that self-sorting of complex DCL takes place, and that component exchange can be used to deliberately disassemble the cage.
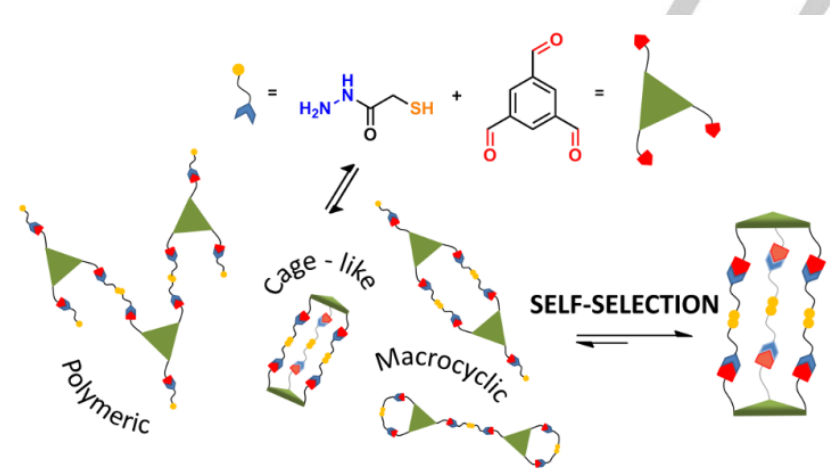

Scheme 1. Generation of dynamic combinatorial libraries from aromatic aldehyde and thioglycolic hydrazide using acylhydrazone and disulfide reversible covalent reactions, and examples of the various polymeric, macrocyclic, and cage constituents that can be expressed in the system.

\section{Results and Discussion}

We first investigated the potential of our approach using commercially-available aromatic compound, Benzene-1,3,5tricarboxAldehyde (BENZ-ALD ${ }_{3}$ ), and the heterobifunctional compound thioglycolic hydrazide $\mathbf{1}$ (Fig. 1). While the former can undergo up to three acylhydrazone-forming reactions, the latter can be involved in both acylhydrazone and disulfide formation. Therefore, the system can potentially yield a rich DCL made of many structurally and morphologically distinct products from linear through cyclic species to larger cage-type products (Scheme 1). However, based on our previous findings on disulfide-based system, ${ }^{[19 a]}$ we suspected that thanks to weak supramolecular interactions (e.g. $\pi$ - $\pi$-stacking, hydrogen bonds) and entropically favoured formation of cage architectures over polymeric species, the former should significantly emerge from this DCL. Subsequently, we became interested in inserting fluorescent aromatic components. Indeed, cages containing a fluorescent reporter can be useful for sensing applications. We selected TetraPhenylEthene (TPE) for their fluorescent properties that display Aggregation-Induced Emission (AIE). ${ }^{[6]}$ TPE compounds typically exhibit low fluorescent emission in solution due to the existence of multiple relaxation pathways that are enabled by the free rotation of the phenyl rings. However, in an aggregated state, this rotation is restricted, resulting in an enhanced fluorescence emission. We reasoned that if the formation of the cage compounds involves $\pi$-stacking interactions, it should become visible by an increase in fluorescence emission. We therefore synthesized TPE-ALD in two-steps starting from 1,1,2,2-tetraphenylethene (Fig. 1 and scheme S1). Finally, wishing to expand the scope of our approach by enabling further chemical modifications, we synthesized a short heterobifunctional spacer, Cys-Hyd, which bears a functionalizable amine.<smiles>O=Cc1cc(C=O)cc(C=O)c1</smiles>

BENZ-ALD 3<smiles>O=Cc1ccc(C(=C(c2ccc(C=O)cc2)c2ccc(C=O)cc2)c2ccc(C=O)cc2)cc1</smiles><smiles>NNC(=O)CSSCC(=O)NN</smiles>

Figure 1. Structure of Benzene-1,3,5-tricarboxAldehyde (BENZ-ALD (B), , 1,1,2,2-tetraphenylethene (TPE-ALD), thioglycolic hydrazide (1 and $\mathbf{1}_{\mathbf{2}}$ ), and cysteine hydrazide Cys-Hyd.

Tripodal cage, Cage 1. We screened mixtures of aqueous buffers at different $\mathrm{pH}$ values, with DMSO as an organic cosolvent for improving the solubility as well as facilitating disulfide formation and exchange. At the concentration of $5 \mathrm{mM}$ and above, we observed precipitate formation upon mixing of BENZ$\mathbf{A L D}_{3}$ (1 equiv.) with $\mathbf{1}$ (3 equiv.), even with different content of DMSO (10-75\%) as a co-solvent. Lowering the concentration of BENZ-ALD ${ }_{3}$ to $2 \mathrm{mM}$, together with three equivalents of 1 in a mixture of aqueous buffer and DMSO (25/75 v/v) gave us optimal conditions with homogeneous solution at all $\mathrm{pH}$ range. LC-MS was used to monitor the outcome of the reaction and to characterize the constitution of the DCL. Surprisingly, a 
maximum of two products, out of the many combinations that are virtually possible, were observed (Fig. 2A). After two days of incubation at $\mathrm{pH}=6$, the reaction reached completion and led to the formation of a single product. ESI mass spectrometry analysis (Fig. 2C) indicated that this product corresponds to the cage-type structure (Cage 1, Fig. 2D), in which two aromatics are linked through three spacers - each spacer combining two thiol components. Longer reaction times, respectively 6 and 7 days, were necessary at $\mathrm{pH}=5$ and $\mathrm{pH}=7$ to reach the same composition (Fig. S1-S3). Only when carried out at $\mathrm{pH}=9$ the reaction showed low conversion with multiple products formed, among which the cage was not detected (Fig. S4).

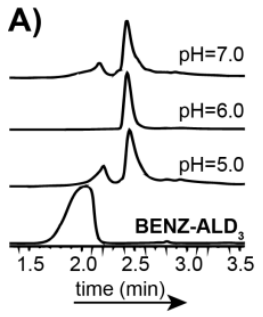

C)

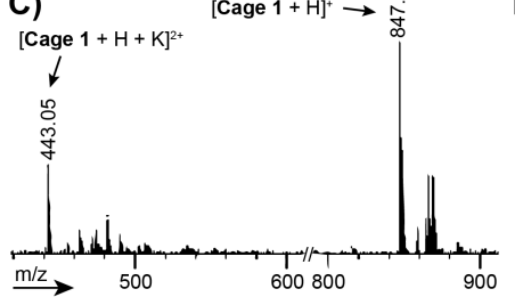

B)

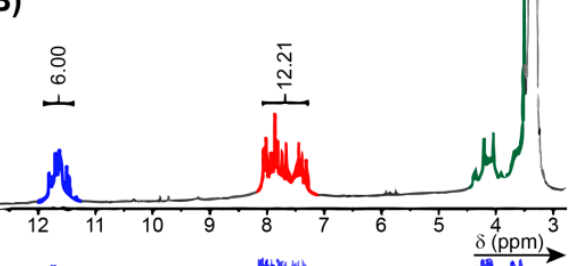

D)

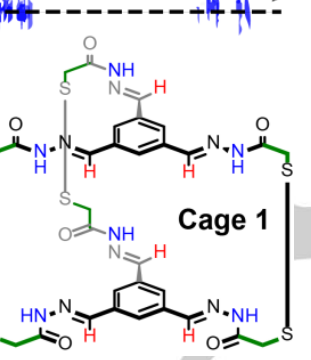

Figure 2. A) HPLC chromatograms $(254 \mathrm{~nm})$ of the reaction between BENZ$\mathbf{A L D}_{3}$ (1 equiv.) and thioglycolic hydrazide $\mathbf{1}$ (3 equiv.) in aqueous buffer/DMSO 25/75 (v/v), after 2 days at different $\mathrm{pH}$; B) ${ }^{1} \mathrm{H}$ NMR $(600 \mathrm{MHz}$, $d_{6}$-DMSO) of Cage 1 with, below, the extracted DOSY NMR spectrum; C) ES mass spectrum of Cage $1\left(\mathrm{~m} / \mathrm{z}\right.$ calcd. for $[\mathrm{cage}+\mathrm{H}+\mathrm{K}]^{2+} 443.05$, for $[\mathrm{cage}+\mathrm{H}]^{+}$ $847.00 ; \mathrm{D})$ proposed structure of the cage compound Cage 1.

${ }^{1} \mathrm{H}$ NMR spectrum shows the complete disappearance of the aldehyde peak (10.3 ppm) and the formation of new set of signals at $11.5 \mathrm{ppm}$ which is typical region for $-\mathrm{C}(\mathrm{O}) \mathrm{N} H \mathrm{~N}=$ protons of acylhydrazones (Fig. 2B). We also noticed the disappearance of the $-\mathrm{CH}_{2}$-S- peak at $3.0 \mathrm{ppm}$ and a new peak formed at $3.4 \mathrm{ppm}$. By comparing with the ${ }^{1} \mathrm{H}$ NMR spectrum of the disulfide compound $\mathbf{1}_{\mathbf{2}}$ - which was formed by spontaneous oxidation in DMSO (Fig. S5-S6) - we found that this new peak corresponds to the chemical shift of $-\mathrm{CH}_{2}-\mathrm{S}-\mathrm{S}-\mathrm{CH}_{2}$, thereby demonstrating that the new compound formed contains both acylhydrazone and disulfide linkages (Fig. S7). However, multiple peaks are observed in the ${ }^{1} \mathrm{H}$ NMR spectrum which may indicate that several isomers are present. Indeed, when taking into account $E / Z$ imine, cis/trans amide, and disulfide isomers, we found the maximum number of possible isomers to be 225 (Fig. S25). In support of this hypothesis of coexistence of multiple conformational isomers, VT ${ }^{1} \mathrm{H}$-NMR shows partial coalescence of the ${ }^{1} \mathrm{H}$ NMR signals at high temperature (Fig. S16). DOSY NMR was then used to further characterize the system. First of all, we were pleased to see that a single species was found, thereby indicating that the self-assembly yields a single type of product, even though isomers indiscernible by DOSY NMR are clearly formed. Secondly, DOSY NMR shows the size of this self-assembled compound to be significantly larger than the starting BENZ-ALD 3 , with solvodynamic radius and spherical volume being respectively 2.5 and 15 times larger, which is compatible with the proposed structure of Cage 1 (Table 1 and Fig. 2B, S8-S9). Taken altogether, these data confirm the self-selection and effective formation of Cage 1 from the DCL generated by mixing stoichiometric amounts of BENZ$\mathrm{ALD}_{3}$ and thioglycolic hydrazide 1.

The formation of Cage 1 requires the one-pot assembly of eight components through six acylhydrazones and three disulfide bonds. Its exclusive formation by self-selection within the DCL indicates a high thermodynamic stability compared to all the other compounds that can virtually be present in the $\mathrm{DCL}$, which drives its self-selection and amplification. This is most likely caused by specific intramolecular non-covalent interactions, as also previously observed by Alfonso et al. in other systems. ${ }^{[27]}$ Here, we hypothesize that probable $\pi$-stacking interactions between the aromatics and/or hydrogen bonds between the acylhydrazone groups can stabilize this particular cage. To probe the origin of the high stability, we first investigated the importance of medium effect. When the reaction was carried out in pure acetonitrile, a low conversion into the cage was observed and much of the starting materials remained unreacted. This observation shows that the reversible covalent reactions can proceed in this medium but that, in these conditions, the selfassembly does not reach completion. Increasing the proportion of aqueous buffer ( $100 \mathrm{mM}$ AcONa, $\mathrm{pH}=5$ ) from 10 to $25 \%$ favours the formation of the cage compound (Fig. S10-S12). These results show that, in the absence of DMSO as a cosolvent, the aqueous environment is essential for cage formation most probably due to the favoured aggregation of the aromatics which minimises exposure to water and thereby templates cagelike structures. In the latter condition, we noticed that the cage precipitates out (as confirmed by comparative HPLC analyses of the supernatant solution and isolated solid, see Fig. S13), thereby enabling its isolation by simple filtration in a remarkable $40 \%$ overall yield, which amounts to a $90 \%$ isolated yield for each reaction considering nine equivalent reactions involved in the formation of Cage 1. We also varied solvent composition in the presence of DMSO by comparing reactions carried out in pure DMSO, DMSO/AcONa buffer $(100 \mathrm{mM}, \mathrm{pH}=5) 75 / 25(\mathrm{v} / \mathrm{v})$, and DMSO/acetonitrile 75/25 (v/v). Albeit the kinetic was slightly affected, we observed cage formation in all three solvents, thereby indicating that both the acylhydrazone and disulfide formation can effectively take place when DMSO is present (Fig. S14-S15). 
Table 1. Hydrodynamic radii and spherical volumes calculated using StokesEinstein equation from the DOSY NMR data.

\begin{tabular}{ccccc}
\hline Entry & Compounds & $\mathrm{D}\left[\mathrm{m}^{2} \mathrm{~s}^{-1}\right]$ & $\mathrm{r}_{\text {hyd }}[\AA]$ & $\mathrm{v}_{\text {sph }}\left[\AA^{3}\right]$ \\
\hline 1 & BENZ-ALD $_{3}$ & $4.8 \times 10^{-10}$ & 2.3 & 50.0 \\
2 & Cage 1 & $1.95 \times 10^{-10}$ & 5.6 & 746.3 \\
\hline
\end{tabular}

D: Diffusion coefficient; $r_{\text {hyd: }}$ Hydrodynamic radius ; $v_{\text {sph }}$ : Spherical volume.

Fluorescent tetrapodal cage, Cage 2. In the next step, the covalent self-assembly between TPE-ALD ( $2 \mathrm{mM}, 1$ equiv.) and 1 (4 equiv.) was investigated. Due to solubility reasons, the previously employed solvents could not be applied, therefore an increased amount of DMSO (DMSO/ $\left.\mathrm{H}_{2} \mathrm{O} 94 / 6 \mathrm{v} / \mathrm{v}\right)$ was used. LC-MS analysis of the resulting DCL showed the complete conversion, within 3 days, of the starting TPE-ALD into a single new product (Fig. 3A). The same product was observed when the reaction was carried out in $100 \%$ DMSO. Gratifyingly, this product was identified by mass spectrometry as the expected cage compound Cage 2 which results from the one-pot assembly of 10 components through 12 covalent bonds (8 acylhydrazones +4 disulfides) (Fig. 3C and 3D).
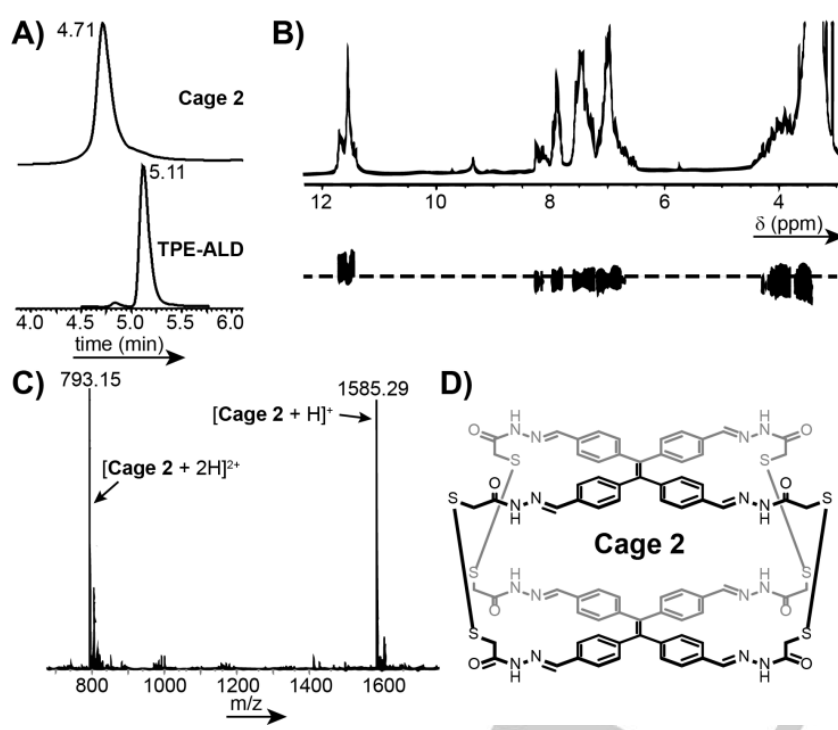

Figure 3. A) HPLC chromatograms of TPE-ALD (bottom), and reaction between TPE-ALD (1 equiv.) and thioglycolic hydrazide 1 (4 equiv.) in $\mathrm{DMSO} / \mathrm{H}_{2} \mathrm{O} 94 / 6(\mathrm{v} / \mathrm{v})$ after 6 days (top); B) ${ }^{1} \mathrm{H}$ NMR $\left(600 \mathrm{MHz}, d_{6}\right.$-DMSO) of Cage 2 with, below, the extracted DOSY NMR spectrum; C) ESI mass spectrometry analysis of Cage 2 (m/z calcd for $[\text { cage }+2 \mathrm{H}]^{2+} 793.15$, for $\left.[\text { cage }+\mathrm{H}]^{+} 1585.29 ; \mathrm{D}\right)$ proposed structure of the cage compound Cage 2.

Given the possibilities of imine, amide, and disulfide isomers, the maximum number of isomers of Cage 2 is 400 (Fig. S26), which most probably explains the multiple peaks observed in the ${ }^{1} \mathrm{H}$ NMR spectrum (Fig. 3B). DOSY NMR shows the formation of a single type of product that has a solvodynamic radius and a spherical volume, respectively, 2.3 and 40 times larger than TPE-ALD which is compatible with the proposed structure (Table 2, Fig. 3B and S22-S23).
When monitoring the formation of Cage 2 by LC-MS at different time points (Fig. S24), we could observe the formation of intermediates, including the TPE-Intermediate compound made of a single TPE unit in which two intramolecular disulfide bonds were formed (Fig. 4). While the formation of TPE-Intermediate occurs within a few hours, its further conversion into Cage 2 is much slower, which indicates that in these conditions, acylhydrazone formation is faster and that the rate-limiting step for forming Cage 2 rests on intra- to inter-molecular disulfide exchange. In support of this idea, we tested the self-assembly starting with the pre-formed disulfide compound $\mathbf{1}_{\mathbf{2}}$ and found that Cage 2 was formed much faster -1 day instead of 3 days. Similarly, we found that increasing concentration and temperature $\left(50^{\circ} \mathrm{C}\right)$ speed up the conversion of TPEIntermediate into Cage 2.

Table 2. Hydrodynamic radii and spherical volumes calculated using StokesEinstein equation from the DOSY NMR data.

\begin{tabular}{ccccc}
\hline Entry & Compounds & $\mathrm{D}\left[\mathrm{m}^{2} \mathrm{~s}^{-1}\right]$ & $\mathrm{r}_{\text {hyd }}[\AA]$ & $\mathrm{v}_{\mathrm{sph}}\left[\AA^{3}\right]$ \\
\hline 1 & TPE-ALD & $4.77 \times 10^{-10}$ & 2.3 & 51.0 \\
2 & Cage 2 & $1.39 \times 10^{-10}$ & 7.9 & 2060.5 \\
\hline
\end{tabular}

D: Diffusion coefficient; $r_{\text {hyd: }}$ Hydrodynamic radius; $v_{\text {sph }}$ : Spherical volume.

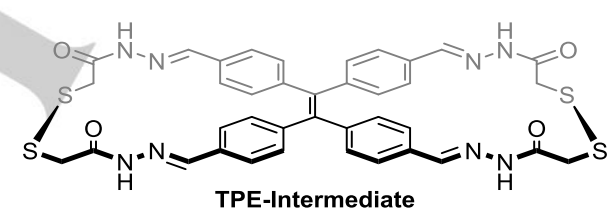

Figure 4. Proposed structure of TPE-Intermediate that is transiently formed during the self-assembly of the cage compound Cage 2 .

Monitoring the covalent self-assembly between TPE-ALD and 1 by UV-Vis spectroscopy shows the gradual appearance of a redshifted band, which is in line with the formation of aromatic acylhydrazones that extend the initial conjugation present in TPE-ALD (Fig 5A). Interestingly, fluorescence spectroscopy shows an overall 61-fold increase in the fluorescence emission during the reaction between TPE-ALD and $\mathbf{1}$ (Fig. 5B). While at low concentration $(0.25 \mathrm{mM})$ we only observed a fluorescence increase (Fig. 5B), a typical blue shift (12 nm) in the fluorescence emission was seen when the reaction was carried out at higher concentration (2 mM) (Fig. 5C). This is explained by the fact that TPE-Intermediate is the main product when the reaction is carried out at low concentration $(0.25 \mathrm{mM})$ whereas Cage 2 becomes the main product when the reaction is carried out at higher concentration $(2 \mathrm{mM})$, as proved by HPLC analyses. Therefore, while the increase in the fluorescence emission of TPE-Intermediate may be due to the rigidification of the system, the blue shift signal can be attributed to the cagehindered arrangement of the TPE units within Cage 2. 

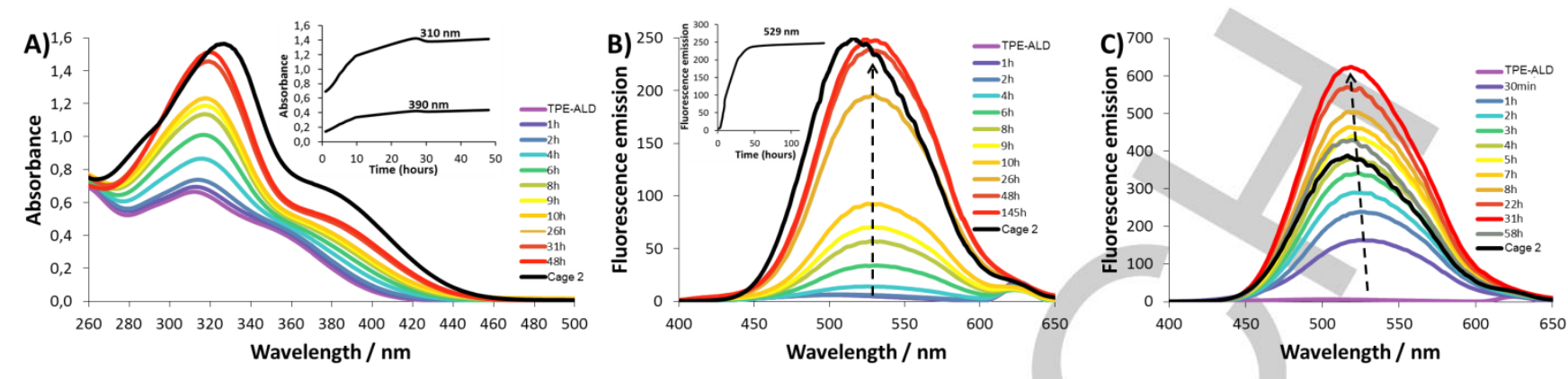

Figure 5. Self-assembly between TPE-ALD and thioglycolic hydrazide 1 in DMSO monitored by A) UV-Visible spectroscopy (reaction carried out at 0.25 mM, the inset shows changes in absorbance at 310 and $390 \mathrm{~nm}$ with time), and fluorescence spectroscopy: B) reaction carried out at $0.25 \mathrm{mM}$ (the fluorescence spectrum of Cage 2 was added for comparison, the inset shows changes in fluorescence emission at $529 \mathrm{~nm}$ with time), C) reaction carried out at 2 mM (a typical blue shift $(12 \mathrm{~nm})$ in the fluorescence emission is observed).

Overall, these results show that self-selection also occurs in the DCL generated from TPE-ALD and thioglycolic hydrazide 1, and leads to the formation of Cage 2. The observation of AIE effects during the self-assembly process shows that aggregation of the TPE units is involved in the formation of Cage 2. Thus, it brings support to the formation of cage-type products and not macrocyclic species (see Scheme 1), which may both have same molecular weights. However, at this stage, we cannot exclude that disulfides may be arranged in a different way than the connectivities represented throughout this manuscript in the structures of cage compounds. For instance, isomers such as Pacman structures - which can be considered as open-cage structures - may also exist (Fig. S27). ${ }^{[28]}$ Unfortunately, despite many attempts, we have not yet been successful in obtaining single crystals suitable for X-ray crystallography analysis which would help determining the exact molecular structures.

Functionalized cages, Cage 3. Hydrazides and thiols can be readily introduced in peptides. Therefore, as a first step toward the generation of functionalized cages, we extended our approach by using the simplest and shortest heterobifunctional spacer, Cys-Hyd, which contains an amine that can be used as a reactive site for introducing additional groups.

Cys-Hyd was synthesized in three steps using a solution-phase approach (Scheme 2). The commercially available protected amino acid Fmoc-Cys(Trt)-OH was engaged in a coupling reaction with tert-butylcarbazate mediated by EDC/HOBt to afford Fmoc-Cys(Trt)-Hyd-Boc in $97 \%$ yield. Then, the Fmoc group was removed by reaction with piperidine in DMF to give the corresponding Cys(Trt)-Hyd-Boc in 56\% yield. Finally, the deprotection of the Boc and Trt protecting groups by a TFA/TIS/ $\mathrm{H}_{2} \mathrm{O}$ (95:2.5:2.5) solution yielded the desired Cys-Hyd. Satisfyingly, LC-MS analyses revealed that the reaction between TPE-ALD (2 mM, 1 equiv.) and Cys-Hyd (4 equiv.) leads to complete conversion and formation of a single species which is identified by mass spectrometry as the desired cage Cage 3 (Fig $6 \mathrm{~A}-6 \mathrm{C}$ ). Fluorescence spectroscopy confirms that a strong fluorescence emission enhancement takes place concomitantly to the cage formation (Fig. 6D).

This result paves the way toward functionalized self-assembled cages that can be obtained either by post-functionalization of Cage $\mathbf{3}$ or through cage formation with $\mathrm{N}$-functionalized cysteine-hydrazide.

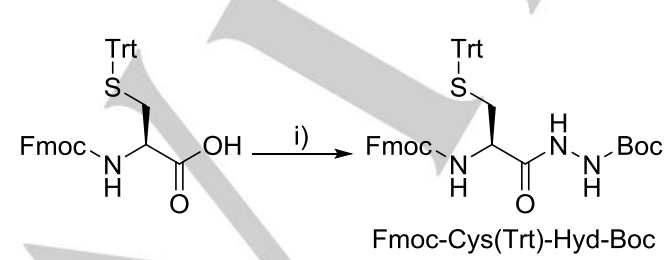<smiles>CC#CCNC(CS[Tl])C(=O)NNC(=O)C#CC#CC(=O)OC(C)(C)C</smiles>

Scheme 2. Synthesis of Cys-Hyd. Reagents and conditions: i) tert-butylcarbazate, EDC, $\mathrm{HOBt}, \mathrm{Et}_{3} \mathrm{~N}, \mathrm{CH}_{2} \mathrm{Cl}_{2} \mathrm{O}^{\circ} \mathrm{C}$ to rt; ii) DMF/piperidine (8/2), rt iii) TFA/TIS/ $\mathrm{H}_{2} \mathrm{O}$ $(95 / 2.5 / 2.5)$, rt. 
A)

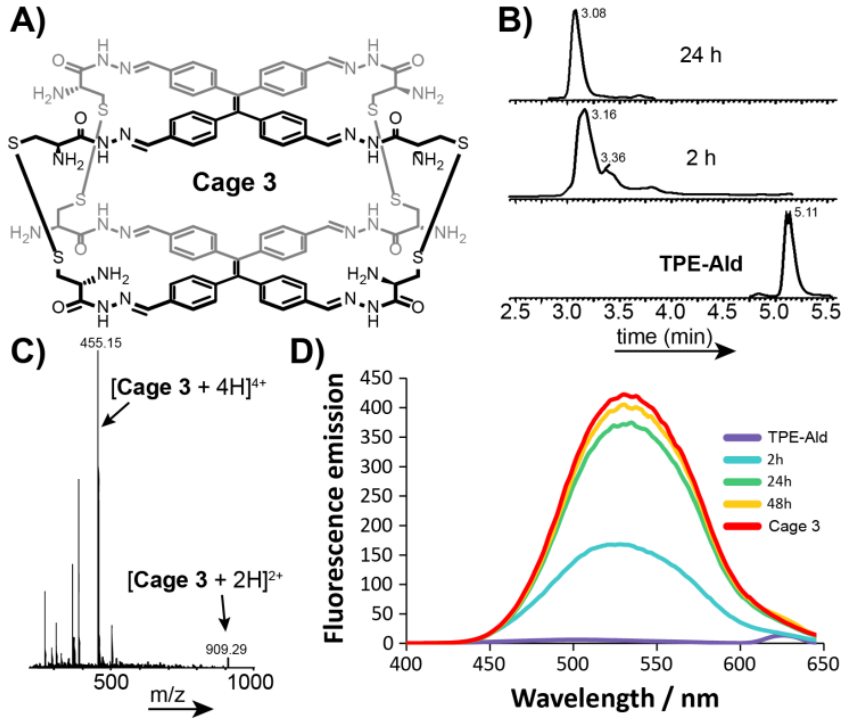

Figure 6. A) Structure of Cage 3; B) HPLC chromatograms of TPE-ALD and reaction between TPE-ALD (1 equiv.) and Cys-Hyd (4 equiv.) in DMSO/ $\mathrm{H}_{2} \mathrm{O}$ $94 / 6(\mathrm{v} / \mathrm{v})$ after 2 and 24 hours; C) ESI mass spectrometry analysis ( $\mathrm{m} / \mathrm{z}$ calcd. for $[\text { cage }+4 \mathrm{H}]^{4+} 455.13$, for $[\mathrm{cage}+2 \mathrm{H}]^{2+} 909.25$; D) self-assembly of Cage 3 monitored by fluorescence spectroscopy.

Self-sorting of cages. The self-assembly methodology based on reversible covalent reactions enables complex systems to correct and adapt their constitution until forming the most stable structures. Therefore, if allowed by thermodynamics, self-sorting of $\mathrm{DCL}$ can be observed. ${ }^{[29]}$ Here we studied stoichiometric mixtures of both BENZ-ALD $\mathbf{B}_{3}$ and TPE-ALD with either thioglycolic hydrazide $\mathbf{1}$ or its corresponding disulfide $\mathbf{1}_{\mathbf{2}}$, which can form a wide range of constituents, including mixed cages. However, we found by HPLC analysis that the two cages, tripodal Cage 1 and tetrapodal Cage 2, are the main products expressed by this complex system (Fig. 7 and S36). We noticed a new product (retention time 4.2 min, see Fig. 7) - possibly a mixed compound only present as a minor component of the system - whose identity could unfortunately not be determined from the extracted ESI mass spectrum. This narcissistic selfsorting behaviour, previously observed in metallosupramolecular cages, ${ }^{[20 \mathrm{~b}, 30]}$ can result from an optimization of spatial distribution of connectivities between the aromatic platforms and lateral arms within the two cage compounds. Thus, the observation of self-sorting within this DCL brings further support to the formation of closed cage-type products. Indeed, open macrocyclic species are expected to be less constrained and therefore to accommodate more easily mixed structures combining BENZ-ALD 3 and TPE-ALD, thereby generating statistical DCL instead of self-sorted DCL.

Cage opening by dynamic covalent exchange. Cages selfassembled through reversible covalent reactions may be interconverted through dynamic covalent exchange. Here, we tested the opening of the cages by exchange of the acylhydrazones with methoxyamine - a reaction that is thermodynamically shifted toward the more stable oxime product.
HPLC analyses confirms that upon incubation with methoxyamine (20 equivalents), Cage 2 is fully converted into the tetra-oxime compound TPE-Oxime (Fig. 8A-8B) ${ }^{[31]}$ In addition, fluorescence spectroscopy shows the decrease of fluorescence emission (Fig. 8C), thereby confirming that Cage 2 dissociates.

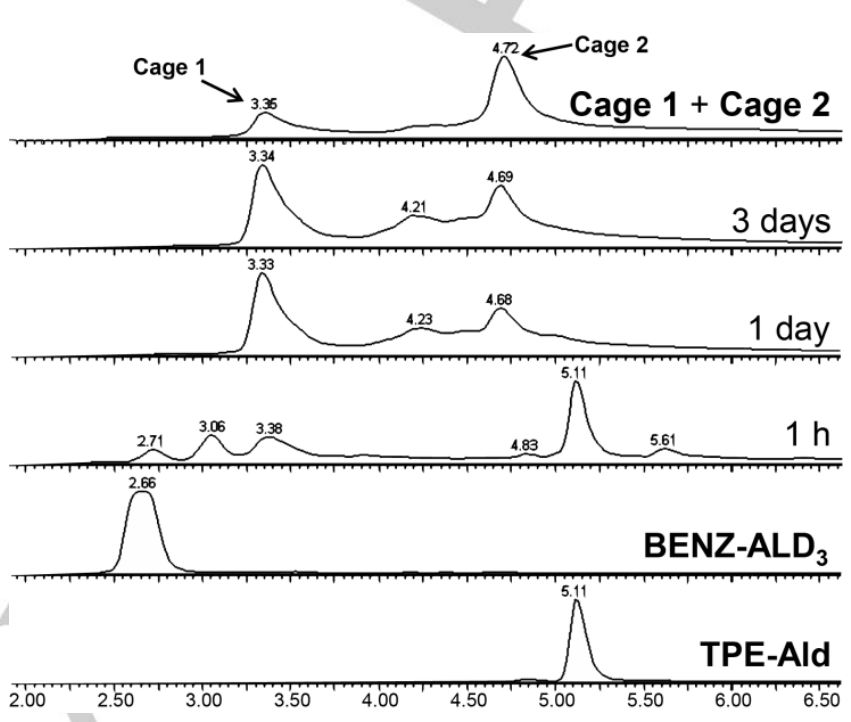

Figure 7. HPLC monitoring after 1 hour, 1 day, and 3 days of a reaction between BENZ-ALD 3 (1 equiv.), TPE-ALD (1 equiv.) and 1 (7 equiv.), and comparison with a reference mixture of Cage 1 and Cage 2.

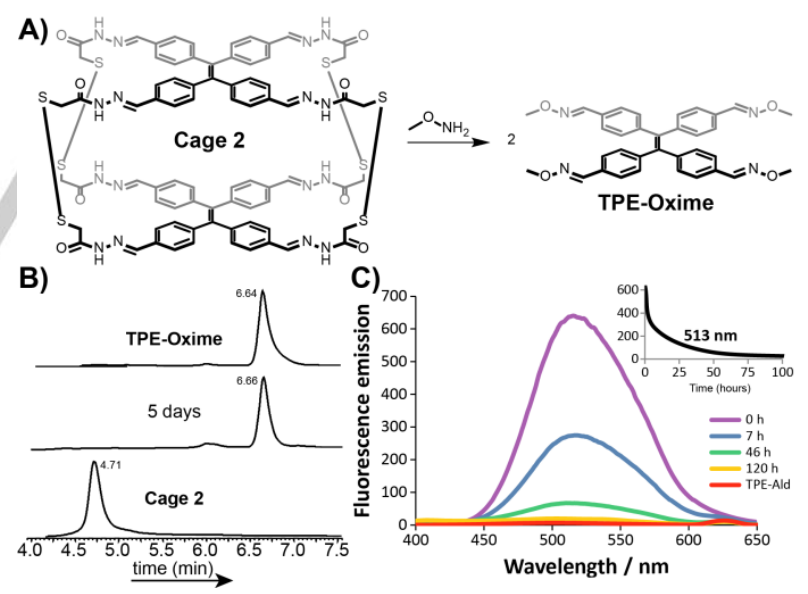

Figure 8. A) Process of opening of Cage 2 by component exchange with methoxyamine; B) HPLC monitoring, from bottom to top: Cage 2, after 5 days of reaction with methoxyamine, TPE-Oxime; C) fluorescence emission during the reaction of Cage 2 with methoxyamine (inset shows changes in fluorescence emission at $513 \mathrm{~nm}$ with time).

\section{Conclusions}

We reported herein the facile preparation of a new class of tripodal and tetrapodal aromatic cage-type compounds that are self-assembled in one-pot using simultaneous dynamic covalent 
reactions, namely acylhydrazone and disulfide bonds formation. This is the first example of multicomponent cage formation in aqueous media by applying simultaneously two distinct dynamic covalent bonds. The exclusive formation - self-selection - of these complex structures from dynamic combinatorial libraries may be the result of intramolecular interactions and/or geometric/connectivity fit which would also explain the narcissistic self-sorting behaviour observed. This methodology enables the effective access to complex cage-type nanostructures. We also demonstrated that functional groups can be easily introduced, thereby allowing future post-synthetic functionalization. Interestingly, we successfully identified a fluorescent tetrapodal cage which assembly and disassembly can be monitored by fluorescence spectroscopy. Finally, this methodology enables controlling the disassembly of the cage by a deliberate thermodynamically-driven component exchange. This straightforward bottom-up self-assembly approach is expected to facilitate the generation of functional cages. Future studies will focus on assessing the molecular recognition properties of these cage compounds.

\section{Experimental Section}

Materials and Methods. Solvents and benzene-1,3,5-tricarboxaldehyde were purchased from commercial suppliers and used without further purification. Thioglycolic hydrazide $\mathbf{1}$ was synthesized as previously described. ${ }^{[32]}$ 1,1,2,2-tetrakis(4-bromophenyl)ethane (TPE-Br) was prepared according to a literature procedure. ${ }^{[33]}$ Dry DMF and THF were obtained by a solvent purification system PureSolve MD5 from Innovative Technology. Preparative purifications were performed by silica gel flash column chromatography (Merck® 40-60 $\mu \mathrm{M}$ ). Solvents used as eluents are technical grade.

HPLC analyses were performed on a Waters HPLC 2695 (EC Nucleosil 300-5 $C_{18}, 125 \times 3 \mathrm{~mm}$ ) column, Macherey - Nagel) equipped with a Waters 996 DAD detector. The following linear gradients of solvent $B$ $(90 \%$ acetonitrile, $9.9 \%$ water, and $0.1 \%$ TFA) into solvent $A(99.9 \%$ water and $0.1 \%$ TFA) were used: 0 to $95 \%$ of solvent B in 5 min; flow 1 $\mathrm{ml} / \mathrm{min}$. Retention time $\left(\mathrm{t}_{\mathrm{R}}\right)$ are given in minutes.

LC/MS analyses were performed on a Shimadzu LCMS2020 (Phenomex Kinetex $\mathrm{C}_{18}, 2.6 \mu \mathrm{m} * 7.5 \mathrm{~cm}, 100 \AA$ ) equipped with a SPD-M20A detector with the following linear gradient of solvent $\mathrm{B}(99.9 \%$ acetonitrile, $0.1 \%$ $\mathrm{HCOOH}$ ) and solvent $A(99.9 \%$ water and $0.1 \% \mathrm{HCOOH}): 5$ to $95 \%$ of solvent $B$ in $5 \mathrm{~min}$; flow $1 \mathrm{ml} / \mathrm{min}$. Retention times $\left(\mathrm{t}_{\mathrm{R}}\right)$ are given in minutes.

Fluorescence analyses were carried out on an AF-2500 HITACH fluorescence spectrophotometer. UV-Vis absorption experiment was measured on UV-3100pC UVisco spectrophotometer.

IR spectra were recorded on a Perkin Elmer Spectrum 2 FTIR spectrophotometer.

${ }^{1} \mathrm{H}$ NMR, ${ }^{13} \mathrm{C}\left\{{ }^{1} \mathrm{H}\right\}$ NMR, VT and DOSY NMR spectra were recorded at $400 \mathrm{MHz}$ for ${ }^{1} \mathrm{H}$ and $100 \mathrm{MHz}$ for ${ }^{13} \mathrm{C}$ (Bruker Avance 400), or $600 \mathrm{MHz}$ for ${ }^{1} \mathrm{H}$ and $150 \mathrm{MHz}$ for ${ }^{13} \mathrm{C}$ (Bruker Avance III) in deuterated solvents. Chemical shifts are reported in ppm relative to the residual solvent peak. Data are reported as follows: Chemical shift $(\delta)$, multiplicity (s for singlet, $\mathrm{d}$ for doublet, $\mathrm{t}$ for triplet, $\mathrm{m}$ for multiplet), coupling constant ( $\mathrm{J}$ in Hertz), and integration. DOSY NMR spectroscopy was carried out at the Laboratoire de Mesures Physiques, IBMM, Université de Montpellier. Hydrodynamic radii are calculated using the Stokes-Einstein equation.
ESI-MS analyses were carried out at the Laboratoire de Mesures Physiques, IBMM, Université de Montpellier using Micromass Q-Tof instruments.

Elemental analyses were performed using an Elementar Vario Micro Cube instrument.

Synthesis of 1,1,2,2-tetrakis(4-carboxaldehydephenyl)ethene (TPEAld). To a solution of 1,1,2,2-tetrakis(4-bromophenyl)ethene $(650 \mathrm{mg}, 1$ $\mathrm{mmol})$ in dry THF $(25 \mathrm{~mL})$ at $-78^{\circ} \mathrm{C}, 2.7 \mathrm{~mL}(7 \mathrm{mmol}, 7$ equiv. $)$ of a $2.5 \mathrm{M}$ $n$-butyllithium solution in hexanes $(2.5 \mathrm{M})$ were added dropwise. The mixture was stirred at this temperature during $2 \mathrm{~h}$ and then, at $0^{\circ} \mathrm{C}$ during 1h. After cooling at $-78^{\circ} \mathrm{C}, 0.62 \mathrm{~mL}(8 \mathrm{mmol}, 8$ equiv.) of dry DMF was added. The mixture was then warmed at room temperature and stirred overnight. The reaction was quenched with $\mathrm{HCl}(2 \mathrm{M})(50 \mathrm{~mL})$. The aqueous layer was extracted with diethyl ether $(3 \times 50 \mathrm{~mL})$. The combined extracts were then dried over $\mathrm{MgSO}_{4}$, filtered and evaporated under reduced pressure. The residue was purified by column chromatography on silica gel eluting with a gradient of dichloromethane:diethyl ether (98:2 to $92: 8$ ) to give the title compound as a pale yellow solid Yield : $28 \%$ (0.12 g). IR (ATR): $v_{\mathrm{CO}}=1694 \mathrm{~cm}^{-1}$. ${ }^{1} \mathrm{H} \mathrm{NMR}\left(300 \mathrm{MHz}, \mathrm{CDCl}_{3}\right): \delta=9.94$ (s, $4 \mathrm{H}, \mathrm{CHO}), 7.68\left(\mathrm{~d},{ }^{3} J_{\mathrm{H}-\mathrm{H}}=8.2 \mathrm{~Hz}, 8 \mathrm{H}, \mathrm{CH}=\mathrm{CH}\right), 7.18\left(\mathrm{~d},{ }^{3} \mathrm{~J}_{\mathrm{H}-\mathrm{H}}=8.2 \mathrm{~Hz}\right.$ $8 \mathrm{H}, \mathrm{CH}=\mathrm{CH}) .{ }^{13} \mathrm{C}\left\{{ }^{1} \mathrm{H}\right\} \mathrm{NMR}\left(75 \mathrm{MHz}, \mathrm{CDCl}_{3}\right): \delta=191.5(\mathrm{CHO}), 148.0$, 142.3, 135.5, 131.9, 129.7 ppm. HR-MS (ESI-TOF ${ }^{+}$): m/z Calcd $\mathrm{C}_{30} \mathrm{H}_{21} \mathrm{O}_{4}$ 445.1440 (M+H); found 445.1438. Anal. Calcd for $\mathrm{C}_{30} \mathrm{H}_{20} \mathrm{O}_{4}(444.14): \% \mathrm{C}$ $81.07, \% \mathrm{H} 4.54$; found \% $81.30, \% \mathrm{H} 4.92$.

Synthesis of Fmoc-Cys(Trt)-Hyd-Boc. Tert-butyl carbazate $(251 \mathrm{mg}$, $3.41 \mathrm{mmol}$ ) and 1-hydroxybenzotriazole hydrate (HOBt, $692 \mathrm{mg}, 5.12$ mmol) were added to a solution of Fmoc-Cys(Try)-OH (2 g, $3.41 \mathrm{mmol})$ and triethylamine $(522 \mu \mathrm{L}, 3.76 \mathrm{mmol})$ in dry dichloromethane $(190 \mathrm{mM})$ Then, the solution was cooled to $0^{\circ} \mathrm{C}$ and $\mathrm{N}$ - (3-dimethylaminopropyl)- $\mathrm{N}$ 'ethylcarbodiimide hydrochloride (EDC, $982 \mathrm{mg}, 5.12 \mathrm{mmol}$ ) was added The reaction mixture was then warmed to room temperature and stirred overnight. After removal of the solvent, the residue was diluted with EtOAc $(100 \mathrm{~mL})$, washed with a saturated $\mathrm{NaHCO}_{3}$ solution $(30 \mathrm{~mL})$ and brine ( $30 \mathrm{~mL})$, dried over anhydrous $\mathrm{Na}_{2} \mathrm{SO}_{4}$, and concentrated in vacuo. The resulting crude material was purified by flash chromatography (cyclohexane/EtOAc gradient 9:1 to 7:3, v/v) to provide Fmoc-Cys(Trt)Hyd-Boc with $97 \%$ yield as a white solid. $R_{f}=0.37$ (cyclohexane/EtOAc $8: 2, \mathrm{v} / \mathrm{v}) ; \mathrm{t}_{\mathrm{R}}=5.54 \mathrm{~min}\left(\right.$ Method A); ${ }^{1} \mathrm{H}$ NMR $\left(400 \mathrm{MHz}\right.$, DMSO- $\left.\mathrm{d}_{6}\right): \delta=$ 9.79 (s, 1H, NH-NH-Boc), 8.76 (s, 1H, NH-NH-Boc), $7.88\left(\mathrm{~d}, 2 \mathrm{H},{ }^{3} \mathrm{~J}_{\mathrm{H}-\mathrm{H}}=\right.$ $7.6 \mathrm{~Hz}, \mathrm{CHC}(\mathrm{C}) \mathrm{CH}=\mathrm{CH}), 7.77-7.75(\mathrm{~m}, 3 \mathrm{H}, \mathrm{NH}-\mathrm{Fmoc}+\mathrm{CHCCH}=\mathrm{CH})$, 7.42-738 $(\mathrm{m}, 2 \mathrm{H}, \mathrm{CH}=\mathrm{CH}), 7.35-7.23(\mathrm{~m}, 17 \mathrm{H}, \mathrm{CH}=\mathrm{CH}), 4.28-4.15(\mathrm{~m}$, $\left.4 \mathrm{H}, \mathrm{NHCHCH}_{2}+\mathrm{OCH}_{2} \mathrm{CH}\right), 2.46-2.32\left(\mathrm{~m}, 2 \mathrm{H}, \mathrm{NHCHCH}_{2}\right), 1.36(\mathrm{~s}, 9 \mathrm{H}$, $\left.\mathrm{OC}\left(\mathrm{CH}_{3}\right)_{3}\right) ;{ }^{13} \mathrm{C}\left\{{ }^{1} \mathrm{H}\right\}$ NMR $\left(100 \mathrm{MHz}\right.$, DMSO-d $\left.\mathrm{d}_{6}\right): \delta=169.5,155.6,155.0$, 144.3, 143.7, 140.7, 129.1, 128.1, 127.7, 127.1, 126.8, 125.5, 120.1, 79.1, 65.9, 65.8, 52.3, 46.6, 34.1, 28.0; HRMS (ESI): $\mathrm{m} / \mathrm{z}$ calcd for $\left[\mathrm{C}_{42} \mathrm{H}_{41} \mathrm{~N}_{3} \mathrm{O}_{5} \mathrm{~S}+\mathrm{Na}\right]^{+} 722.2665$, found 722.2661 .

Synthesis of H-Cys(Trt)-Hyd-Boc. Fmoc-Cys(Trt)-Hyd-Boc (2.3 g, 3.31 $\mathrm{mmol}$ ) was dissolved in a solution of DMF/piperidine $(8: 2, \mathrm{v} / \mathrm{v} ; 70 \mathrm{mM})$. The reaction solution was stirred overnight at room temperature and then concentrated in vacuo. The resulting crude material was purified by flash chromatography $\left(\mathrm{CH}_{2} \mathrm{Cl}_{2} / \mathrm{MeOH}\right.$ gradient $99: 1$ to $98: 2$, v/v) and by semipreparation HPLC to provide $\mathrm{H}-\mathrm{Cys}(\mathrm{Trt})-\mathrm{Hyd}-\mathrm{Boc}$ with $56 \%$ yield as a white solid. $\mathrm{R}_{\mathrm{f}}=0.34\left(\mathrm{CH}_{2} \mathrm{Cl}_{2} / \mathrm{AcOEt} 8: 2, \mathrm{v} / \mathrm{v}\right) ; \mathrm{t}_{\mathrm{R}}=3.17 \mathrm{~min}($ Method $\mathrm{A})$; ${ }^{1} \mathrm{H}$ NMR $(400 \mathrm{MHz}, \mathrm{MeOD}): \delta=7.42-7.39(\mathrm{~m}, 6 \mathrm{H}, \mathrm{CCH}=\mathrm{CH}), 7.32-7.27$ $(\mathrm{m}, 6 \mathrm{H}, \mathrm{CCH}=\mathrm{CH}), 7.25-7.21(\mathrm{~m}, 3 \mathrm{H}, \mathrm{CCH}=\mathrm{CH}=\mathrm{CH}), 3.17-3.14(\mathrm{~m}, 1 \mathrm{H}$, $\left.\mathrm{CHCH}_{2}\right), 2.65-2.61\left(\mathrm{~m}, 1 \mathrm{H}, \mathrm{CHCH}_{2} \mathrm{a}\right), 2.42-2.37\left(\mathrm{~m}, 1 \mathrm{H}, \mathrm{CHCH}_{2} \mathrm{~b}\right), 1.45$ $\left(\mathrm{s}, 9 \mathrm{H}, \mathrm{OC}\left(\mathrm{CH}_{3}\right)_{3}\right) ;{ }^{13} \mathrm{C}\left\{{ }^{1} \mathrm{H}\right\} \mathrm{NMR}\left(100 \mathrm{MHz}\right.$, DMSO-d $\left.\mathrm{d}_{6}\right): \delta=173.1,154.8$, 143.7, 129.1, 128.3, 127.1, 79.7, 66.4, 49.8, 32.3, 28.0; HRMS (ESI): $\mathrm{m} / \mathrm{z}$ calcd for $\left[\mathrm{C}_{27} \mathrm{H}_{31} \mathrm{~N}_{3} \mathrm{O}_{3} \mathrm{~S}+\mathrm{H}\right]^{+} 478.2164$, found 478.2161 . 
Synthesis of Cys-Hyd. H-Cys(Trt)-Hyd-Boc was dissolved in $\mathrm{TFA} / \mathrm{TIS} / \mathrm{H}_{2} \mathrm{O}(95 / 2.5 / 2.5)$ solution $(50 \mathrm{mM})$ and stirred for overnight at room temperature. After removal of $90 \%$ of the solvent, diethyl ether was added to the residue. The precipitate was triturated with $\mathrm{Et}_{2} \mathrm{O}$ and filtered. The crude material was then lyophilized twice to afford the product $\mathrm{H}$ Cys-Hyd with $10 \%$ yield as a white solid. The number of mole of CysHyd was calculated by ${ }^{1} \mathrm{H}$ NMR titration method using tert-butyl alcohol as an internal reference. ${ }^{1} \mathrm{H}$ NMR $(400 \mathrm{MHz}, \mathrm{MeOD}): \delta=3.95\left(\mathrm{t}, 1 \mathrm{H},{ }^{3} \mathrm{~J}\right.$. $\left.\mathrm{H}=6.16 \mathrm{~Hz}, \mathrm{CHCH}_{2}\right), 3.08-2.90\left(\mathrm{~m}, 2 \mathrm{H}, \mathrm{CHCH}_{2}\right) ;{ }^{13} \mathrm{C}\left\{{ }^{1} \mathrm{H}\right\} \mathrm{NMR}(100 \mathrm{MHz}$, MeOD): $\delta=163.6,55.1,26.2$; HRMS (ESI): $\mathrm{m} / \mathrm{z}$ calcd for $\mathrm{C}_{3} \mathrm{H}_{10} \mathrm{~N}_{3} \mathrm{OS}^{+}\left[\mathrm{M}+\mathrm{H}^{+}\right]$136.0545, found 136.0541 .

\section{Acknowledgements}

We thank Aurélien Lebrun for DOSY experiments. We thank the CNRS, the French Embassy in Poland and the French Foreign ministry (PHC POLONIUM 35134RH), and the LabEx CheMISyst (ANR-10-LABX-05-01) for funding. We also thank National Centre for Research and Development (grant LIDER/024/391/L-5/13/NCBR/2014), and Polish Ministry of Science and Higher Education (grant IUVENTUS PLUS 0446/IP3/2015/73) and National Science Centre (grant PRELUDIUM UMO-2016/21/N/ST5/00849) for financial support. C.K and S.R. are grateful to the Région Languedoc-Roussillon (grant "Chercheurs d'Avenir - 2015, 005984) and the FEDER (Fonds Européen de Développement Régional) for financial support.

Keywords: Cage $\cdot$ Hydrazone $\cdot$ Disulfide $\cdot$ Dynamic covalent chemistry $\cdot$ Self-assembly

[1] a) A. Galan, P. Ballester, Chem. Soc. Rev. 2016, 45, 1720-1737; b) S. Zarra, D. M. Wood, D. A. Roberts, J. R. Nitschke, Chem. Soc. Rev. 2015, 44, 419-432; c) F. Hof, S. L. Craig, C. Nuckolls, J. Rebek, Angew. Chem. Int. Ed. 2002, 41, 1488-1508; d) S. R. Seidel, P. J. Stang, Acc. Chem. Res. 2002, 35, 972-983.

[2] a) M. M. J. Smulders, I. A. Riddell, C. Browne, J. R. Nitschke, Chem. Soc. Rev. 2013, 42, 1728-1754; b) M. Fujita, M. Tominaga, A. Hori, B. Therrien, Acc. Chem. Res. 2005, 38, 369-378.

[3] D. Ajami, J. Rebek, Acc. Chem. Res. 2013, 46, 990-999.

[4] a) S. J. Rowan , S. J. Cantrill, G. R. L. Cousins, J. K. M. Sanders, J. F. Stoddart, Angew. Chem. Int. Ed. 2002, 41, 898-952; b) Y. H. Jin, C. Yu, R. J. Denman, W. Zhang, Chem. Soc. Rev. 2013, 42, 6634-6654.

[5] a) G. Zhang, M. Mastalerz, Chem. Soc. Rev. 2014, 43, 1934-1947; b) Y. H. Jin, Q. Wang, P. Taynton, W. Zhang, Acc. Chem. Res. 2014, 47, 1575-1586; c) M. Mastalerz, Angew. Chem. Int. Ed. 2010, 49, 5042-5053.

[6] a) M. Mondal, A. K. H. Hirsch, Chem. Soc. Rev. 2015, 44, 2455-2488; b) S. Ulrich, P. Dumy, Chem. Commun. 2014, 50, 5810-5825; c) A. Herrmann, Chem. Soc. Rev. 2014, 43, 1899-1933; d) M. C. Misuraca, E. Moulin, Y. Ruff, N. Giuseppone, New J. Chem. 2014, 38, 3336-3349; e) J. W. Li, P. Nowak, S. Otto, J. Am. Chem. Soc. 2013, 135, 92229239; f) F. B. L. Cougnon, J . K. M. Sanders, Acc. Chem. Res. 2012, 45, 2211-2221; g) R. A. R. Hunt, S. Otto, Chem. Commun. 2011, 47, 847-858; h) S. Ladame, Org. Biomol. Chem. 2008, 6, 219-226; i) K.
Severin, Chem. Eur. J. 2004, 10, 2565-2580; $\mathrm{j}$ O. Ramström, J.-M. Lehn, Nat. Rev. Drug Discov. 2002, 1, 26-36; k) J. -M. Lehn, Chem. Eur. J. 1999, 5, 2455-2463.

[7] P. Mal, D. Schultz, K. Beyeh, K. Rissanen, J. R. Nitschke, Angew. Chem. Int. Ed. 2008, 47, 8297-8301.

[8] a) H. M. Seifert, K. R. Trejo, E. V. Anslyn, J. Am. Chem. Soc. 2016, 138, 10916-10924; b) S. Lascano, K. D. Zhang, R. Wehlauch, K. Gademann, N. Sakai, S. Matile, Chem. Sci. 2016, 7, 4720-4724; c) K. D. Zhang, S. Matile, Angew. Chem. Int. Ed. 2015, 54, 8980-8983; d) A. Wilson, G. Gasparini, S. Matile, Chem. Soc. Rev. 2014, 43, 1948-1962; e) V. Goral, M. I. Nelen, A. V. Eliseev, J. -M. Lehn, Proc. Natl. Acad. Sci. USA 2001, 98, 1347-1352.

[9] Z. Rodriguez-Docampo, S. Otto, Chem. Commun. 2008, 5301-5303.

[10] A. G. Orrillo, A. M. Escalante, R. L. E. Furlan, Chem. Commun. 2008 , 5298-5300

[11] M. E. Bracchi, D. A. Fulton, Chem. Commun. 2015, 51, 11052-11055.

[12] a) M. J. Barrell, A. G. Campana, M. von Delius, E. M. Geertsema, D. A. Leigh, Angew. Chem. Int. Ed. 2011, 50, 285-290; b) M. von Delius, E. M. Geertsema, D. A. Leigh, Nature Chem. 2010, 2, 96-101.

[13] J. Atcher, I. Alfonso, RSC Adv. 2013, 3, 25605-25608.

[14] a) J. L. Sun, J. L. Bennett, T. J. Emge, R. Warmuth, J. Am. Chem. Soc. 2011, 133, 3268-3271; b) C. Givelet, J. L. Sun, D. Xu, T. J. Emge, A. Dhokte, R. Warmuth, Chem. Commun. 2011, 47, 4511-4513; c) Z. H. Lin, T. J. Emge, R. Warmuth, Chem. Eur. J. 2011, 17, 9395-9405; d) X. J. Liu, R. Warmuth, J. Am. Chem. Soc. 2006, 128, 14120-14127; e) X. J. Liu, Y. Liu, G. Li, R. Warmuth, Angew. Chem. Int. Ed. 2006, 45, 901904.

[15] J. L. Culshaw, G. Cheng, M. Schmidtmann, T. Hasell, M. Liu, D. J. Adams, A. I. Cooper, J. Am. Chem. Soc. 2013, 135, 10007-10010.

[16] T. Hasell, X. F. Wu, J. T. A. Jones, J. Bacsa, A. Steiner, T. Mitra, A. Trewin, D. J. Adams, A. I. Cooper, Nat. Chem. 2010, 2, 750-755.

[17] Y. Zhang, Y. M. Legrand, A. van der Lee, M. Barboiu, Eur. J. Org. Chem. 2016, 1825-1828.

[18] S. P. Black, J. K. M. Sanders, A. R. Stefankiewicz, Chem. Soc. Rev. 2014, 43, 1861-1872.

[19] a) A. R. Stefankiewicz, J. K. M. Sanders, Chem. Commun. 2013, 49, 5820-5822; b) A. R. Stefankiewicz, M. R. Sambrook, J. K. M. Sanders, Chem. Sci. 2012, 3, 2326-2329.

[20] a) J. Mosquera, B. Szyszko, S. K. Y. Ho, J. R. Nitschke, Nature Comm 2017, 8, b) T. K. Ronson, D. A. Roberts, S. P. Black, J. R. Nitschke, J. Am. Chem. Soc. 2015, 137, 14502-14512; c) W. J. Meng, B. Breiner, K. Rissanen, J. D. Thoburn, J. K. Clegg, J. R. Nitschke, Angew. Chem. Int. Ed. 2011, 50, 3479-3483.

[21] C. F. Ke, H. Destecroix, M. P. Crump, A. P. Davis, Nat. Chem. 2012, 4, 718-723.

[22] a) E. Faggi, C. Vicent, S. V. Luis, I. Alfonso, Org. Biomol. Chem. 2015 13,11721-11731; b) I. Marti, M. Bolte, M. I. Burguete, C. Vicent, I. Alfonso, S. V. Luis, Chem. Eur. J. 2014, 20, 7458-7464; c) E. Faggi, A. Moure, M. Bolte, C. Vicent, S. V. Luis, I. Alfonso, J. Org. Chem. 2014, 79, 4590-4601; d) A. Moure, S. V. Luis, I. Alfonso, Chem. Eur. J. 2012, 18, 5496-5500.

[23] M. Zhang, M. L. Saha, M. Wang, Z. Zhou, B. Song, C. Lu, X. Yan, X. Li, F. Huang, S. Yin, P. J. Stang, J. Am. Chem. Soc. 2017, 139, 5067-5074. 
[24] K. D. Okochi, G. S. Han, I. M. Aldridge, Y. L. Liu, W. Zhang, Org. Lett. 2013, 15, 4296-4299.

[25] a) B. Icli, N. Christinat, J. Tonnemann, C. Schuttler, R. Scopelliti, K. Severin, J. Am. Chem. Soc. 2009, 131, 3154-3155; b) N. Christinat, R. Scopelliti, K. Severin, Angew. Chem. Int. Ed. 2008, 47, 1848-1852; c) M. Hutin, G. Bernardinelli, J. R. Nitschke, Chem. Eur. J. 2008, 14, 4585-4593.

[26] a) J. Mei, Y. N. Hong, J. W. Y. Lam, A. J . Qin, Y. H. Tang, B. Z. Tang, Adv. Mater. 2014, 26, 5429-5479; b) Y. N. Hong, J. W. Y. Lam, B. Z. Tang, Chem. Soc. Rev. 2011, 40, 5361-5388.

[27] a) M. Lafuente, J. Atcher, J. Sola, I. Alfonso, Chem. Eur. J. 2015, 21, 17002-17009; b) J. Sola, M. Lafuente, J. Atcher, I. Alfonso, Chem. Commun. 2014, 50, 4564-4566.

[28] a) J. B. Love, Chem. Commun. 2009, 3154-3165; b) K. Raatikainen, J. Huuskonen, E. Kolehmainen, K. Rissanen, Chem. Eur. J. 2008, 14, 3297-3305.
[29] a) Z. F. He, W. Jiang, C. A. Schalley, Chem. Soc. Rev. 2015, 44, 779789; b) M. L. Saha, M. Schmittel, Org. Biomol. Chem. 2012, 10, 4651 4684; c) M. M. Safont -Sempere, G. Fernandez, F. Wurthner, Chem. Rev. 2011, 111, 5784-5814; d) A. X. Wu, L. Isaacs, J. Am. Chem. Soc. 2003, 125, 4831-4835.

[30] N. Sinha, T. T. Y. Tan, E. Peris, F. E. Hahn, Angew. Chem. Int. Ed. 2017, 56, 7393-7397.

[31] The full characterization data of TPE-Oxime can be found in the Supporting Information.

[32] E. Bartolami, J. Knoops, Y. Bessin, M. Fossépré, J. Chamieh, P. Dumy, M. Surin, S. Ulrich, Chem. Eur. J. 2017, DOI: 10.1002/chem.201702974

[33] A. Schultz, S. Laschat, S. Diele, M. Nimtz, Eur. J. Org. Chem. 2003, 15, 2829-2839.

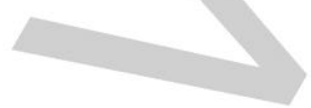


Entry for the Table of Contents (Please choose one layout)

Layout 1:

\section{FULL PAPER}

Multi-component aromatic cages are self-assembled, self-sorted, and reconfigured in aqueous solutions through two simultaneous dynamic covalent reactions, hydrazone and disulfide.

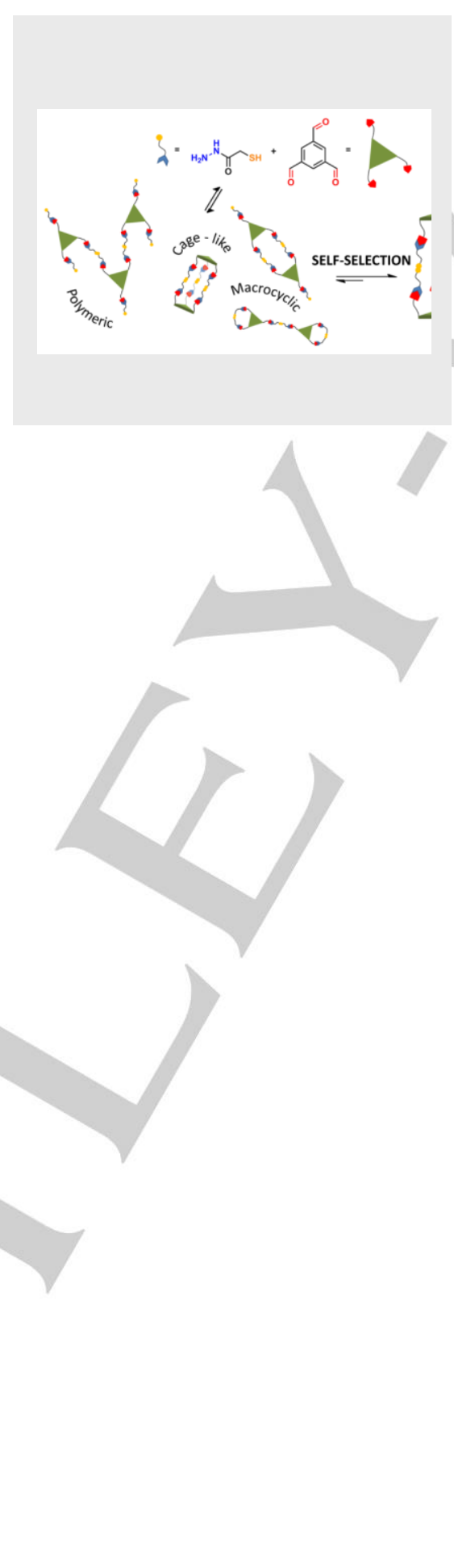

Wojciech Drożdż, Camille Bouillon, Clément Kotras, Sébastien Richeter, Mihail Barboiu, Sébastien Clément, Artur R. Stefankiewicz, ${ }^{*}$ Sébastien Ulrich*

Page No. - Page No.

Generation of Multicomponent Molecular Cages using Simultaneous Dynamic Covalent Reactions 